\title{
Determinants of persistent post-COVID-19 symptoms: value of a novel COVID-19 symptom score
}

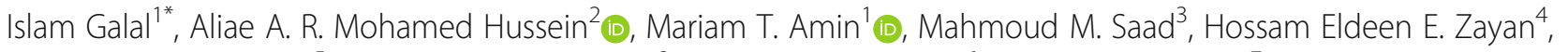
Mustafa Z. Abdelsayed ${ }^{5}$, Mohamed M. Moustafa², Abdel Rahman Ezzat ${ }^{6}$, Radwa E. D. Helmy ${ }^{7}$, Howida K. Abd_Elaal ${ }^{5}$, Nasrallah A. Al Massry ${ }^{8}$, Mohamed A. Soliman ${ }^{1}$, Asmaa M. Ismail ${ }^{1}$, Karima M. S. Kholief ${ }^{3}$, Enas Fathy ${ }^{9}$ and Maiada K. Hashem ${ }^{10}$

\begin{abstract}
Background: Being a newly emerging disease, little is known about its long-lasting post-COVID-19 consequences. The aim of this work is to assess the frequency, patterns, and determinants of persistent post-COVID-19 symptoms and to evaluate the value of a proposed novel COVID-19 symptom score. Patients with confirmed COVID-19 in a hospital-based registry were included in a cross-sectional study (the hospitals including Assiut University Hospital, Assiut Chest Hospital, Aswan University Hospital, and Aswan Specialized Hospital). The patient demographics, comorbid disorders, the mean duration since the onset of the symptoms, history of hospital or ICU admittance, and the treatment taken during the acute state, as well as symptom score before and after convalescence, were recorded.

Results: The most frequent constitutional and neurological symptoms were myalgia (60.0\%), arthralgia (57.2\%), restriction of daily activities (57.0\%), and sleeping troubles (50.9\%), followed by anorexia (42.6\%), chest pain (32.6\%), gastritis (32.3\%), cough (29.3\%), and dyspnea (29.1\%). The mean total score of acute stage symptoms was $31.0 \pm$ 16.3 while post-COVID 19 symptom score was $13.1 \pm 12.6(P<0.001)$. The main determinants of the persistent postCOVID-19 symptoms were the need for oxygen therapy $(P<0.001)$, pre-existing hypertension $(P=0.039)$, chronic pulmonary disorders $(P=0.012)$, and any chronic comorbidity $(P=0.004)$. There was a correlation between the symptom score during the acute attack and post-COVID-19 stage $(P<0.001, r=0.67)$. The acute phase score had $83.5 \%$ sensitivity and $73.3 \%$ specificity for the cutoff point $>18$ to predict occurrence of post-COVID-19 symptoms.

Conclusions: COVID-19 can present with a diverse spectrum of long-term post-COVID-19 symptoms. Increased acute phase symptom severity and COVID-19 symptom score > 18 together with the presence of any comorbid diseases increase the risk for persistent post-COVID-19 manifestations and severity.
\end{abstract}

Keywords: Post-COVID-19 symptoms, Symptom score, COVID-19 symptom score, Comorbidities, Persistent symptoms

\footnotetext{
*Correspondence: Islamgalal76@yahoo.com; islamgalal@aswu.edu.eg

${ }^{1}$ Aswan Faculty of Medicine, Aswan University, Aswan, Egypt

Full list of author information is available at the end of the article
}

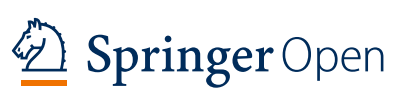

(c) The Author(s). 2021 Open Access This article is licensed under a Creative Commons Attribution 4.0 International License, which permits use, sharing, adaptation, distribution and reproduction in any medium or format, as long as you give appropriate credit to the original author(s) and the source, provide a link to the Creative Commons licence, and indicate if changes were made. The images or other third party material in this article are included in the article's Creative Commons licence, unless indicated otherwise in a credit line to the material. If material is not included in the article's Creative Commons licence and your intended use is not permitted by statutory regulation or exceeds the permitted use, you will need to obtain permission directly from the copyright holder. To view a copy of this licence, visit http://creativecommons.org/licenses/by/4.0/. 


\section{Background}

Being a newly emerging disease a little known about long-lasting post-COVID-19 infection consequences. However, in the coming days, great stress will progressively comprise post-acute carefulness of those recovered cases from COVID-19. It is expected that COVID-19 may have a principal effect on the physical, mental, cognitive, and public health state [1]. Moreover, numerous serious COVID-19 infections necessitate intensive care unit (ICU) management and may lead to persistent postconvalescence consequences comprising respiratory, somatic, mental, and emotional abnormalities which are known as post-intensive care syndrome [2-4]. Recent studies illustrated that in patients who had convalesced from COVID-19, about 50-87\% experienced persistence of at least one symptom, predominantly lethargy and shortness of breath that may necessitate some form of constant carefulness to recover their long-lasting consequences [5, 6]. High blood pressure, obesity, and mental health conditions are proposed risk factors for persistent post-COVID symptoms; however, surprisingly, even young adults and children without underlying chronic medical conditions and those with mild COVID-19 illness reported that they had not returned to their usual state of health several weeks after convalescence [7]. So, further researches are needed to understand the risk factors and pathophysiology of these persistent postCOVID-19 symptoms.

The aim of this work is to assess the frequency, patterns, and determinants of persistent post-COVID-19 symptoms and to evaluate the value of a proposed novel COVID-19 symptom score.

\section{Methods}

The present study was a cross-sectional study performed from 18th of July to 31st of August 2020. Patients were included if they had confirmed COVID-19 in a hospitalbased registry (positive or indeterminate COVID-19 PCR test, or presumed presence of COVID-19 based on clinical and radiological criteria). They were interviewed in the follow-up clinics (the outpatient clinics in the following hospitals including Assiut University Hospital, Assiut Chest Hospital, Aswan University Hospital, and Aswan Specialized Hospital) and filled paper follow-up forms in Arabic language (which is a special form that we formulated for our study). Medical students, residents, and volunteers evaluated patient's symptoms and revised the submitted forms for missing data.

Sample size was calculated using Epi info statistical package version 7. Based on the number of cases in Egypt on 18th July, $2020(86,474)$, the following parameters for cross-sectional study were expected cases with 0.50 , with acceptable margin of error 0.05 , design effect 1, 95\% confidence level. The required sample size was
384 patients. It was raised to 425 after considering $10 \%$ as a dropout.

The following data were collected:

- The patient demographics including age, gender, body mass index, smoking status, history of comorbid disorders, the mean duration since the onset of the symptoms, history of hospital or ICU admittance, and treatment taken during the acute attack were recorded

- Symptoms during the acute attack of COVID-19.

- Symptoms after the convalescence from the acute attack of COVID-19 including general, upper, lower respiratory tract, neurological, cutaneous complaints, and symptoms suggesting other systems of the body affected.

\section{Symptom score}

Two scores were used. Acute stage symptoms include 27 symptoms and post-COVID symptoms include 29 symptoms (comprising newly diagnosed DM and skin rash in addition to the acute stage symptoms). A 4-point Likert scale was used for each symptom reported as absent, mild, moderate, or severe (the score were designed and validated by 2 public health and statistical specialists in Asyut University). For acute stage and post-COVID symptoms, the range of the overall score is $0-81$ and $0-$ 87 , respectively (the higher the number, the further symptom severity).

The study was approved by the ethical committee of Aswan Faculty of Medicine, Egypt (IRB number: aswu/ 469/7/2020) and registered in ClinicalTrial.gov: NCT04479293.

\section{Statistical analysis}

Statistical analyses were performed using IBM SPSS Statistics version 20 (SPSS Inc., Chicago, IL, USA). Categorical data were presented as numbers and percentages, while continuous data were reported as means $\pm \mathrm{SD}$ and/or median (min-max) and tested for normality using the Shapiro-Wilkes test. As symptom score was not normally distributed the Mann-Whitney and Kruskal-Wallis tests were used to compare score according to different variables. Also, Spearman's correlation was used to find the correlation between symptom score in acute and post-COVID-19 stages. To detect the sensitivity and accuracy of acute stage symptom score in the prediction of persistent post-COVID symptoms, ROC curve analysis was performed. In all statistical tests, $p$ value $<0.05$ was considered statistically significant.

\section{Results}

The study involved 430 participants. They were 156 males and 274 females, their mean age was $37.4 \pm 12.6$ 
years, and the range was $12-74$ years. The most common presenting symptoms during the acute attack were myalgia (89.5\%), fever (85.1\%), and restriction of daily activities (84.9\%), while the least frequent complaint was memory loss (21.2\%). Among them, 370 (86\%) reported persistent post-COVID-19 symptoms. The most frequent constitutional and neurological symptoms were myalgia (60.0\%), arthralgia (57.2\%), restriction of daily activities (57.0\%), sleeping troubles (50.9\%), and nervousness and hopelessness (53.3\%), while the most common respiratory and GIT symptoms were anorexia (42.6\%), chest pain (32.6\%), gastritis (32.3\%), cough (29.3\%), and dyspnea (29.1\%), while the least frequent symptom was newly diagnosed DM (8.8\%) (Fig. 1a-c). The mean total score of acute stage symptoms was 31.0 \pm 16.3 while post-COVID 19 symptom score was $13.1 \pm$ $12.6(P<0.001)$.

The mean duration of acute phase in the included group was $9 \pm 3.1$ days; the mean convalescence period was $7 \pm 2.4$ days, while the mean duration of persistent post-COVID-19 symptoms after recovery was $176 \pm$ 35.1 days. The main essential determinant of the persistent post-COVID-19 symptoms and symptom score among the included patients was the need for oxygen therapy $(P<0.001)$ as shown in Table 1 .
There were $26.5 \%$ patients who reported that they have a chronic illness, and the distribution of those conditions is illustrated in Fig. 2. The most frequent preexisting comorbidities allied with the persistent postCOVID-19 symptoms and symptom score among the study population were hypertension $(P=0.039)$ followed by chronic pulmonary disorders $(P=0.012)$, and lastly, the presence of any chronic disorder $(P=0.004)$, as shown in Table 2. There was no difference in post-COVID-19 symptoms and symptom score despite the difference in the received treatment (supportive treatment, hydroxychloroquine, azithromycin, or corticosteroids).

There was a strong positive correlation between the symptom score during the acute attack and postCOVID-19 stage $(P<0.001, r=0.67)$ as illustrated in Fig. 3.

The acute phase score had $83.5 \%$ sensitivity and $73.3 \%$ specificity for the cutoff point $>18$ to predict the occurrence of post-COVID symptoms (Fig. 4).

\section{Discussion}

COVID-19 is a novel illness with limited information on the post- COVID-19 symptoms. The aim of the current study was to identify the essential determinates of the different patterns of these symptoms. Most of the

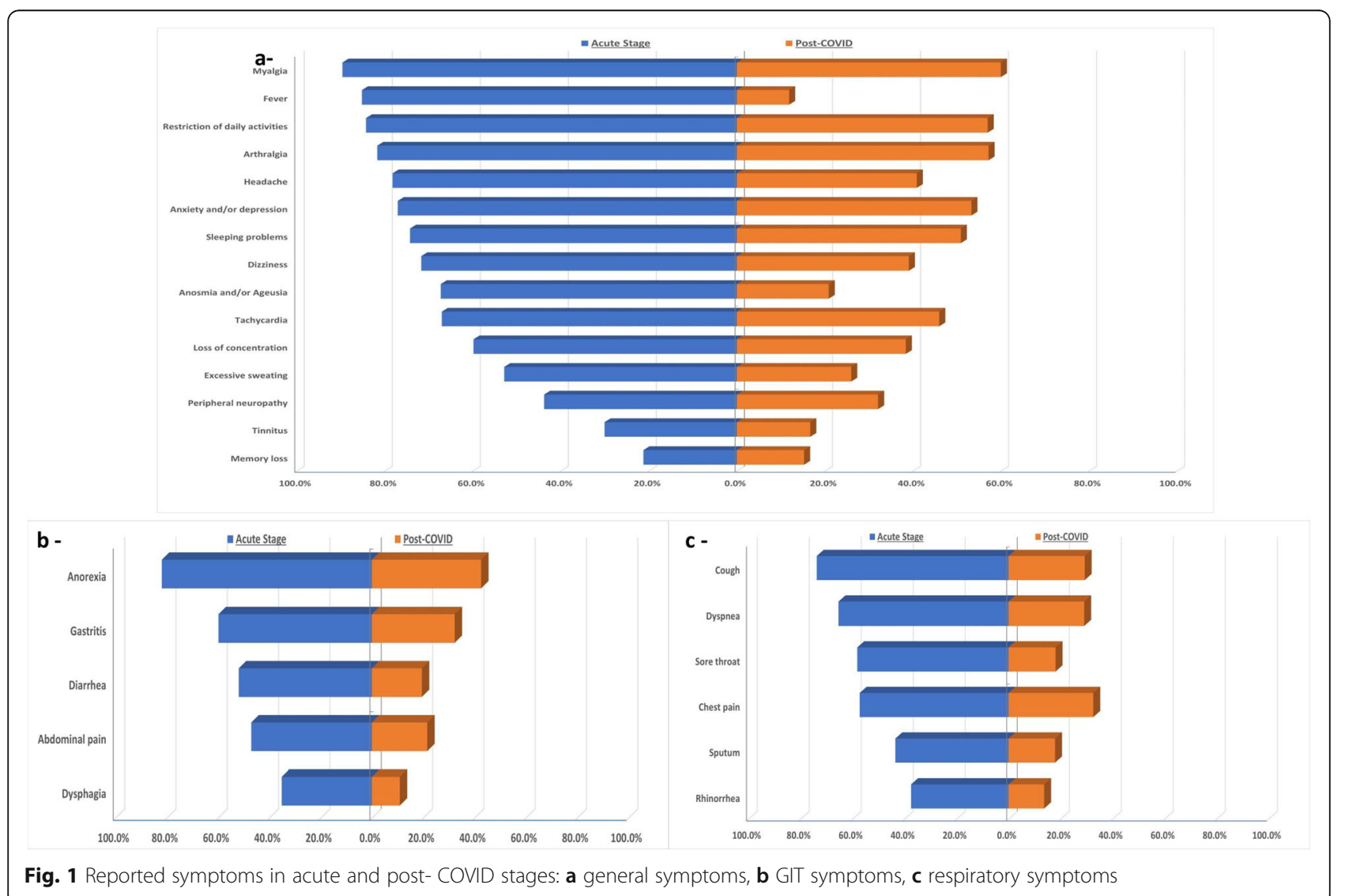


Table 1 Determinants of persistent post-COVID-19 symptoms and symptom score in the included patients $(n=430)$

\begin{tabular}{|c|c|c|c|}
\hline & $N(\%)$ & Mean score & $P$ value* \\
\hline \multicolumn{4}{|l|}{ Age (years) } \\
\hline$<25$ & $58(13.5 \%)$ & $12.9 \pm 13.5$ & 0.393 \\
\hline $25-40$ & $227(52.8 \%)$ & $12.6 \pm 12.3$ & \\
\hline$>40$ & $145(33.7 \%)$ & $14.0 \pm 12.7$ & \\
\hline \multicolumn{4}{|l|}{ Gender } \\
\hline Male & $156(36.3 \%)$ & $13.2 \pm 12.5$ & 0.998 \\
\hline Female & $274(63.7 \%)$ & $13.1 \pm 12.6$ & \\
\hline \multicolumn{4}{|l|}{ BMI } \\
\hline Underweight & $147(34.2 \%)$ & $11.9 \pm 13.6$ & 0.107 \\
\hline Normal & $120(27.9 \%)$ & $13.6 \pm 11.4$ & \\
\hline Overweight & $52(12.1 \%)$ & $14.4 \pm 15.2$ & \\
\hline Obese & $66(15.3 \%)$ & $14.5 \pm 12.6$ & \\
\hline \multicolumn{4}{|l|}{ Smoking } \\
\hline Nonsmoker & $371(86.3 \%)$ & $12.9 \pm 12.8$ & 0.138 \\
\hline Current smoker & $26(6 \%)$ & $13.3 \pm 10.8$ & \\
\hline Ex-smoker & $33(7.7 \%)$ & $16.1 \pm 11.8$ & \\
\hline \multicolumn{4}{|c|}{ Hospital admission during illness } \\
\hline Yes & $103(24 \%)$ & $14.0 \pm 12.4$ & 0.216 \\
\hline No & $327(76 \%)$ & $12.8 \pm 12.7$ & \\
\hline \multicolumn{4}{|c|}{ Need of oxygen therapy } \\
\hline Yes & $72(16.7 \%)$ & $17.4 \pm 12.5$ & $<0.001^{\wedge}$ \\
\hline No & $358(83.3 \%)$ & $12.3 \pm 12.4$ & \\
\hline \multicolumn{4}{|l|}{ ICU admission } \\
\hline Yes & $20(4.7 \%)$ & $17.3 \pm 12.3$ & 0.066 \\
\hline No & 410 (95.3\%) & $12.9 \pm 12.6$ & \\
\hline
\end{tabular}

*Mann-Whitney and Kruskal-Wallis tests were uses

${ }^{\wedge}$ Significant $p$ value

studied population had been still complaining of several persistent post-COVID-19 symptoms. The most frequent constitutional and neurological symptoms were myalgia (60.0\%), arthralgia (57.2\%), restriction of daily activities $(57.0 \%)$, sleeping troubles (50.9\%), and nervousness and hopelessness (53.3\%), while the most common respiratory and GIT symptoms were anorexia $(42.6 \%)$, chest pain (32.6\%), gastritis (32.3\%), cough (29.3\%), and dyspnea (29.1\%). The mean total score of these post-COVID-19 symptoms was $13.1 \pm 12.6$. The main essential determinants of the persistent postCOVID-19 symptoms and symptom score among the included patients were previous seasonal influenza vaccination $(P=0.003)$ and the need for oxygen therapy $(P$ $<0.001)$. Moreover, the most frequent pre-existing comorbidities allied with the persistent post-COVID-19 symptoms and symptom score among the study population were hypertension $(P=0.039)$, followed by chronic pulmonary disorders $(P=0.012)$, and lastly, the presence of any chronic disorder $(P=0.004)$. There was a strong positive correlation between the symptom score during the acute attack and post-COVID-19 stage $(P<0.001, r$ $=0.67)$. Furthermore, the acute phase score had $83.5 \%$ sensitivity and $73.3 \%$ specificity for the cutoff point $>18$ to predict the occurrence of post-COVID symptoms.

By reviewing available literature, about $87 \%$ of those who recovered from COVID-19 infection were still suffering at least one symptom 1 to 2 months after disease onset. A wide spectrum of symptoms was reported including lethargy, breathing difficulty, cough, palpitations/tachycardia, chest pain, sleeping troubles, headache, joint ache, and deterioration of physical and mental well-being [5, 8-12].

On the other hand, an initial report of COVID-19 post-discharge complaints in China summarized that $86.2 \%$ of cases were asymptomatic while only $9.1 \mathrm{had}$ cough and $1.5 \%$ had breathing difficulty that did not affected neither daily activities nor sleep, while dizziness, headache, and lethargy were not reported by those patients at all [13].

The duration of symptom resolution in included COVID-19 cases appears to be longer than that seen in community-acquired pneumonia caused by bacterial pathogens. Previous studies in patients with communityacquired pneumonia found that $97 \%$ of their symptoms recovered by an average of 10 days, while dyspnea resolved after an average of 2 weeks from the onset of the symptom, and lethargy after 3 weeks $[14,15]$.

It is not yet clearly recognized why some patients have persistent recovery. Long-lasting viremia owing to vague or weak or immunological reaction [16], relapse or recontamination [17], inflammatory and other immunological responses [18, 19], de-conditioning [20], and psychological elements such as post-trauma stress syndrome may all added [21, 22]. Moreover, severe COVID19 infections necessitate management in ICU and may lead to persistent post-recovery sequelae including respiratory, physical, mental, and psychological disorders $[2,3]$. These complaints are stated to as post-intensive care syndrome (PICS); these sequelae can have persistent implications on the life quality [4]. Patients suffering PICS commonly report higher prevalence of mental and physical disorders, which may often be long-standing [23]. PICS can also cause disability and reasonable pain [24]. According to Murray et al., about half percent of hospitalized patients for COVID-19 will necessitate constant care to ameliorate their long-standing consequences [6].

Post-recovery symptoms may also be predicted from the preceding coronavirus epidemics of severe acute respiratory syndrome. SARS survivors still had long-lasting lethargy, myalgia, weakness, hopelessness, psychological distress, and sleep abnormalities which may overlay with 


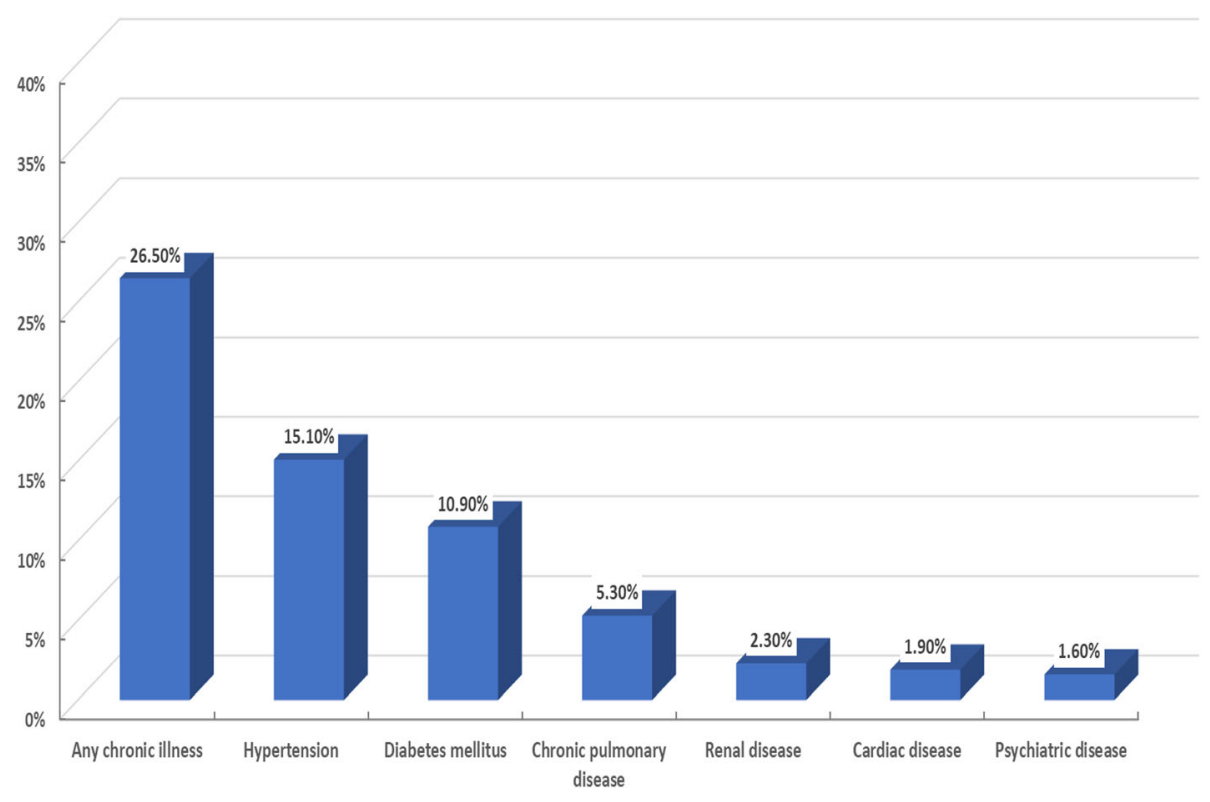

Fig. 2 Associated comorbidities in post-COVID-19 patients included in the study $(n=430)$

the clinical and sleep topographies of fibromyalgia and chronic fatigue syndrome [25]. Myopathy due to corticosteroid use, muscle degenerative changes, and weakness has similarly been described in ARDS survivors during 1-year follow-up period [26]. Another study on the survivors of SARS confirmed deficits in cardio-respiratory performance in 6-min walking test, abnormalities in the musculo-skeletal performance, and quality of life impairment [27]. A similar image was described subsequently after the H1N1 influenza epidemic in 2009 [28]. Following SARS, some cases suffered a decline in their mental well-being during 1-year follow-up period comprising nervousness, hopelessness, high incidence of posttraumatic stress disorders, and psychosis [29].

Moreover, 10 years following SARS recovery, vulnerability to lung contagions, abnormality in glucose absorption, and elevated levels of phosphatidylinositol persist in comparison with healthy ones [30]. A recent meta-analysis found that $25 \%$ of SARS and MERS survivors had diminished lung function, quality of life, and exercise capability at 6 months post-discharge [31]. Similarly, the MERS convalescent cases also reported the ominously lower quality physical health for at least 14 months after the infection start, also survivors who anticipated intensive care unit admittance described an ominously minor inclusive quality of life than those with non-critical disease [32].

In the current study, 29.1\% of included cases had breathing difficulty. This may be explained by some persistent fibrotic changes in the lungs of COVID-19 recovered patients following the current management and discharge rules which may disturb their respiratory function [33]. Moreover, patients with severe COVID-19 criteria may progress to acute respiratory distress syndrome (ARDS) and necessitate mechanical ventilation. ARDS may cause indefinite lung damage, contributing to persistent respiratory disorders after convalescence [34]. Amid 33 and 75\% of cases with COVID-19 necessitate mechanical ventilation, often for a long period, and there are substantial long-term effects allied with prolonged period of intubation $[35,36]$. Those on ventilators are more susceptible to respiratory contagions, which, consecutively, making patients more vulnerable to further risk of irreversible damage of the lung tissue.

There is emergent proof advocating that pulmonary thrombo-embolism is likely an underreported complication allied with COVID-19 that carries actually a major risk of long-standing pulmonary hypertension [37]. Furthermore, prior studies have shown that acute lung

Table 2 Post-COVID-19 symptom score in patients according to comorbidities $(n=430)$

\begin{tabular}{llll}
\hline & Yes & No & $P$ value \\
\hline Diabetes mellitus & $13.4 \pm 11.8$ & $13.1 \pm 12.7$ & 0.730 \\
Hypertension & $15.4 \pm 12.9$ & $12.7 \pm 12.5$ & $0.039^{\wedge}$ \\
Cardiac disease & $13.8 \pm 4.9$ & $13.1 \pm 12.7$ & 0.276 \\
Chronic pulmonary disease & $20.5 \pm 15.6$ & $12.7 \pm 12.3$ & $0.012^{\wedge}$ \\
Renal disease & $16.5 \pm 11.9$ & $13.1 \pm 12.6$ & 0.278 \\
Psychiatric disease & $22.0 \pm 14.2$ & $12.9 \pm 12.5$ & 0.068 \\
$\quad$ Any chronic illness & $15.8 \pm 13.6$ & $12.2 \pm 12.1$ & $0.004^{\wedge}$ \\
\hline
\end{tabular}

"Any chronic illness" means the presence of any comorbid chronic disease including DM, HTN, cardiac, chronic pulmonary, and psychiatric diseases *Mann-Whitney test were uses

^significant $p$ value 


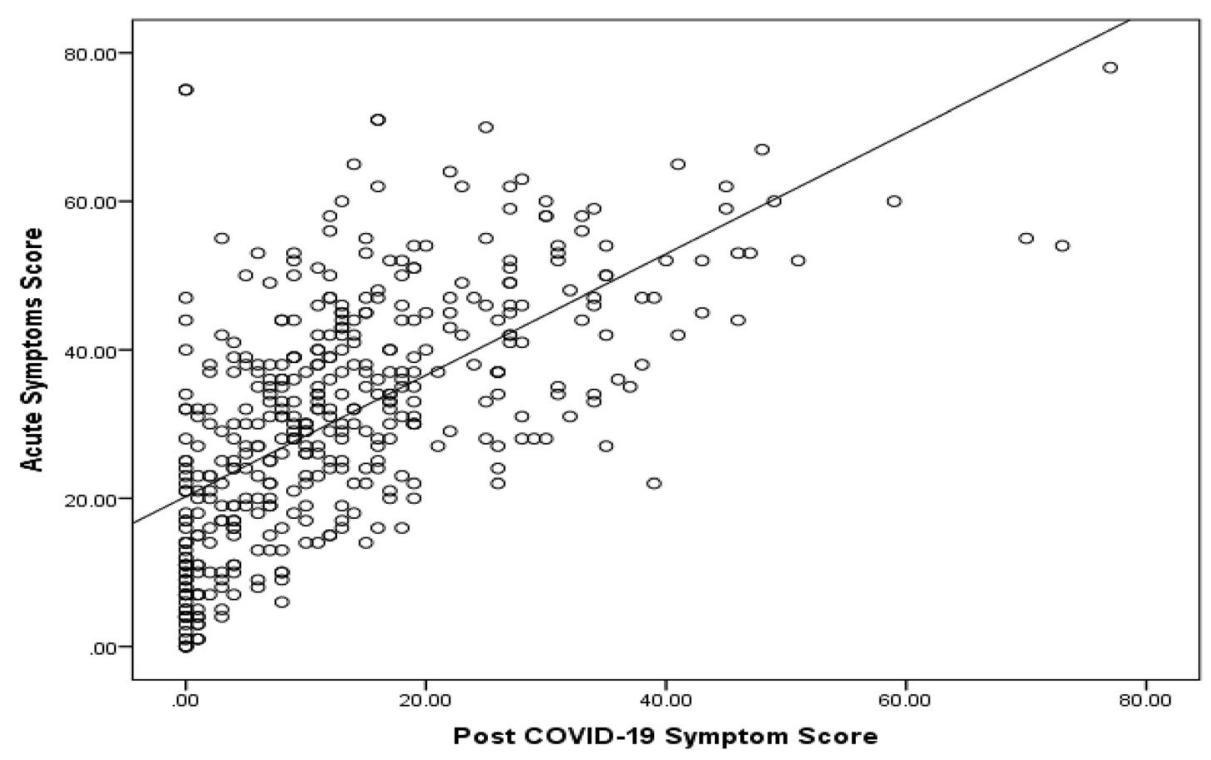

Fig. 3 Correlation between symptom score during acute and post-COVID-19 stage

injury is allied with pulmonary fibrosis on CT scans and associates with restrictive functional pattern and worse quality of life [38].

Thirty-five percent of cases included in this study had nervousness and hopelessness. Consistently, COVID-19 is linked with a major mental health problem in both the acute stage and the chronic term [39]. Nervousness, hopelessness, post-traumatic stress disorder, and sleeplessness are common behind severe coronavirus contagions [40, 41]. Thirty percent of the initial 153 COVID-19 patients in the UK had psychological health troubles comprising neurosis, decline in cognitive

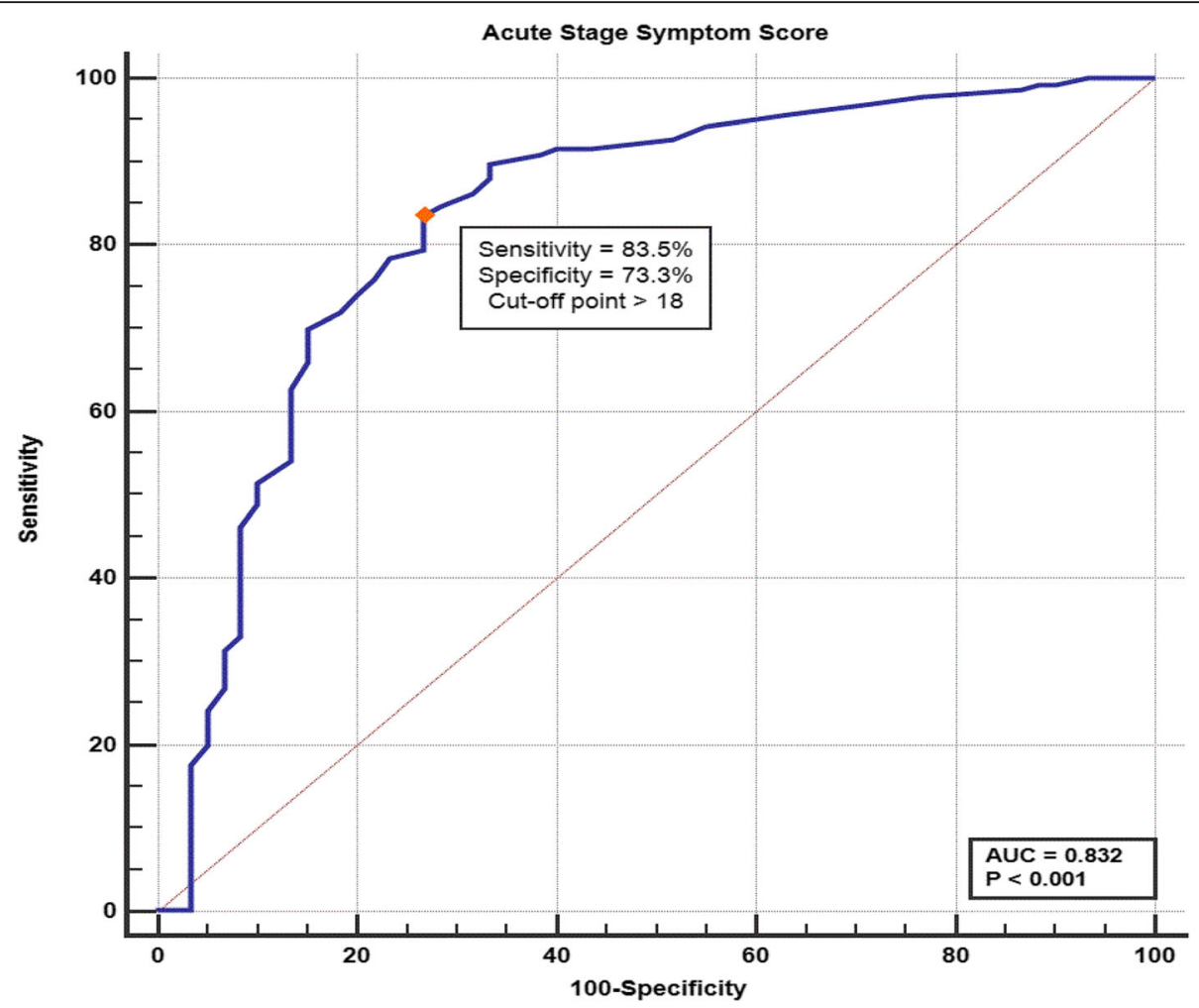

Fig. 4 ROC curve for the acute stage symptom score as a predictor of persistent post-COVID symptoms 
functions, and other disorders [39]. Corticosteroid therapy is also associated with the progression of psychotic complaints [42]. Correspondingly, after SARS, 5-44\% complained of several mental disorders at 1 year comprising nervousness, hopelessness, psychosis, and greater rates of post-trauma stress syndrome [29].

Myalgia (60.0\%) and arthralgia (57.2\%) were common complaints among the patients included in this study. Correspondingly, post-COVID-19 long-lasting pain may distress patients of various age groups, but the elderly patients are the most commonly affected [43]. Similarly, after the acute SARS, some patients may evolve a chronic fatigue syndrome/myalgic encephalomyelitis (CFS/ME)-like a disease with worse sleep quality, lethargy, myalgia, and hopelessness, with some incapable of coming back to their work [25].

Finally, the results of this study are challenged by some limitations. First, the designated sample of post-COVID19 cases is not entirely illustrative of all post-COVID-19 patients. Second, symptoms that initiated after the date of analysis were not verified in this survey. Third, random selection bias may be present and an inability for personal face-to-face interviews in some cases. Finally, our results were made as a single point of follow-up, and further follow-up at 3, 6, or 12 months would aid further understanding of the progression of symptoms postCOVID-19. So, more studies and researches are desired to better appreciate, describe, and identify the persistent post-COVID symptoms in various sceneries and residents.

\section{Conclusions}

COVID-19 is an emerging disease that can present with a diverse spectrum of long-term post-COVID-19 symptoms. All patients may experience post-COVID-19 symptoms; however, increased acute phase symptom severity and score above 18 together with the presence of any comorbid diseases increase the risk for persistent post-COVID-19 manifestations and severity. Physicians and health care employees should aware patients, especially the high-risk group, of the probable long-lasting problems of COVID-19 and reassure them to pursue medical care for any condition they may progress. Moreover, we recommend initiating multi-disciplinary postCOVID-19 recovery units' emphases on prompt and regular communication and socialization, along with physical and neurological assessments and management together with increasing scope for further detailed researches throughout those units.

\section{Abbreviations}

DM: Diabetes mellitus; PCR: Polymerase chain reaction; BMI: Body mass index; GIT: Gastrointestinal symptoms; ROC curve: Receiver operating characteristic curve; CFS/ME: Chronic fatigue syndrome/myalgic encephalomyelitis; SARS: Severe acute respiratory syndrome; MERS: Middle
East respiratory syndrome; ARDS: Acute respiratory distress syndrome; ICU: Intensive care unit; PICS: Post-intensive care syndrome

\section{Acknowledgements}

None.

\section{Authors' contributions}

I G was the principal investigator, formulated the idea, and wrote the first draft of discussion. AMH collected the data, formulated the results, and edited the final draft and revision. MA was responsible for methodology and statistical analysis. MS, $H Z, M A, M M, A E, R H, N A$, and $M S$ were responsible for patient's interview and data collection. $\mathrm{HA}, \mathrm{Al}, \mathrm{KK}, \mathrm{EF}$, and $\mathrm{MH}$ were responsible for data acquisition, review search, and writing the primary draft. The manuscript has been read and approved by all the authors.

\section{Funding}

No financial support was needed.

\section{Availability of data and materials}

The datasets used and/or analyzed during the current study are available from the corresponding author on reasonable request.

\section{Ethics approval and consent to participate}

The Research Ethics Committee at the Faculty of Medicine, Aswan University, has approved the study (IRB number: aswu/469/7/2020) and the study was registered in ClinicalTrial.gov: NCT04479293, and all patients provided written informed consent before participation.

\section{Consent for publication}

The manuscript has been read and approved by all the authors.

\section{Competing interests}

The authors declare that they have no competing interests.

\section{Author details}

${ }^{1}$ Aswan Faculty of Medicine, Aswan University, Aswan, Egypt. ${ }^{2}$ Chest Department, Assiut University Hospitals, Assiut 71515, Egypt. ${ }^{3}$ Assiut Faculty of Medicine, Assiut University, Assiut, Egypt. ${ }^{4}$ Gastroenterology and infectious disease Department, Assiut University Hospitals, Assiut, Egypt. ${ }^{5}$ Assiut University Hospitals, Assiut, Egypt. ${ }^{6}$ Medical Pharmacy, Assiut University, Assiut, Egypt. ${ }^{7}$ Assiut University, Assiut, Egypt. ${ }^{8}$ Al Quds University, Alazhar University, Gaza Branch, Gaza, Palestine. ${ }^{9}$ Department of Cardiovascular Medicine, Faculty of Medicine, Aswan University, Aswan, Egypt. ${ }^{10}$ Chest Department, Assiut Faculty of Medicine, Assiut University Hospitals, Assiut, Egypt.

Received: 4 November 2020 Accepted: 23 December 2020

Published online: 05 February 2021

\section{References}

1. Simpson R, Robinson L (2020) Rehabilitation after critical illness in people with COVID-19 infection. Am J Phys Med Rehabil. 99(6):470-474

2. Denehy L, Elliott D (2012) Strategies for post ICU rehabilitation. Curr Opin Crit Care. 18(5):503-508

3. Jackson JC, Ely EW, Morey MC, Anderson VM, Denne LB, Clune J et al (2012) Cognitive and physical rehabilitation of intensive care unit survivors: results of the RETURN randomized controlled pilot investigation. Crit Care Med 40(4):1088-1097

4. Rawal G, Yadav S, Kumar R (2017) Post-intensive care syndrome: an overview. J Transl Int Med. 5(2):90-92

5. Carfi A, Bernabei R, Landi F (2020) Persistent symptoms in patients after acute COVID-19. JAMA 324(6):603-605

6. Murray A GC, Morris J. We need a Nightingale model for rehab after covid19. 2020. Available from: https://www.hsj.co.uk/commissioning/we-need-anightingale-model-for-rehab-after-covid-19-/7027335.article

7. What we know about Long-term effects of COVID-19: World Healh Organization; 2020 [cited 202009 September ]. Available from: https://www. who.int/docs/default-source/coronaviruse/risk-comms-updates/update-36long-term-symptoms.pdf?sfvrsn=5d3789a6_2 
8. Banda JM, Singh GV, Alser O, Prieto-Alhambra D (2020) Long-term patientreported symptoms of COVID-19: an analysis of social media data. medRxiv the preprint server for health sciences

9. Weerahandi H, Hochman KA, Simon E, Blaum C, Chodosh J, Duan E, et al. Post-discharge health status and symptoms in patients with severe COVID19. medRxiv : the preprint server for health sciences. 2020.

10. Tenforde MW, Kim SS, Lindsell CJ, Billig Rose E, Shapiro NI, Files DC et al (2020) Symptom duration and risk factors for delayed return to usual health among outpatients with COVID-19 in a multistate health care systems network - United States, March-June 2020. MMWR Morb Mortal Wkly Rep 69(30):993-998

11. How long does COVID-19 last? : COVID-19 symptom study; 2020 [cited 2020 June 6]. Available from: https://covid.joinzoe.com/post/covid-long-term

12. Assaf G, Davis H, McCorkell L, Wei H, O'Neill B, Akrami A (2020) What does COVID-19 recovery actually look like? An analysis of the prolonged COVID19 symptoms survey by patient-led research team. The COVID-19 Body Politic Slack Group, London Contract. 2020 May(2)

13. Wang $X, X u H$, Jiang H, Wang L, Lu C, Wei X et al (2020) Clinical features and outcomes of discharged coronavirus disease 2019 patients: a prospective cohort study. QJM. 113(9):657-665

14. Wootton DG, Dickinson L, Pertinez H, Court J, Eneje O, Keogan L et al (2017) A longitudinal modelling study estimates acute symptoms of community acquired pneumonia recover to baseline by 10 days. Eur Respir J. 49(6): 1602170

15. Wyrwich KW, Yu H, Sato R, Powers JH (2015) Observational longitudinal study of symptom burden and time for recovery from communityacquired pneumonia reported by older adults surveyed nationwide using the CAP Burden of Illness Questionnaire. Patient Relat Outcome Meas. 6:215-223

16. Wu Z, Wang Q, Zhao J, Yang P, McGoogan JM, Feng Z et al (2020) Time course of a second outbreak of COVID-19 in Beijing, China, JuneJuly 2020. JAMA. 2020:e2015894. https://doi.org/10.1001/jama.2020. 15894. Epub ahead of print

17. Lan L, Xu D, Ye G, Xia C, Wang S, Li Y et al (2020) Positive RT-PCR test results in patients recovered from COVID-19. JAMA 323(15):1502-1503

18. Colafrancesco S, Alessandri C, Conti F, Priori R (2020) COVID-19 gone bad: a new character in the spectrum of the hyperferritinemic syndrome? Autoimmun Rev 19(7):102573

19. Tay MZ, Poh CM, Rénia L, MacAry PA, Ng LFP (2020) The trinity of COVID-19: immunity, inflammation and intervention. Nat Rev Immunol 20(6):363-374

20. Gemelli Against C-P-ACSG (2020) Post-COVID-19 global health strategies: the need for an interdisciplinary approach. Aging Clin Exp Res 32(8): 1613-1620

21. Forte G, Favieri F, Tambelli R, Casagrande M (2020) COVID-19 Pandemic in the Italian population: validation of a post-traumatic stress disorder questionnaire and prevalence of PTSD symptomatology. Int J Environ Res Public Health. 17(11):415

22. Jiang HJ, Nan J, LV ZY, Yang J (2020) Psychological impacts of the COVID-19 epidemic on Chinese people: exposure, post-traumatic stress symptom, and emotion regulation. Asian Pacific J Trop Med 13(6):252

23. Pandharipande PP, Girard TD, Jackson JC, Morandi A, Thompson JL, Pun BT et al (2013) Long-term cognitive impairment after critical illness. N Engl J Med 369(14):1306-1316

24. Griffiths J, Hatch RA, Bishop J, Morgan K, Jenkinson C, Cuthbertson BH et al (2013) An exploration of social and economic outcome and associated healthrelated quality of life after critical illness in general intensive care unit survivors: a 12-month follow-up study. Crit Care (London, England) 17(3):R100

25. Moldofsky H, Patcai J (2011) Chronic widespread musculoskeletal pain, fatigue, depression and disordered sleep in chronic post-SARS syndrome; a case-controlled study. BMC neurology. 11:37

26. Herridge MS, Cheung AM, Tansey CM, Matte-Martyn A, Diaz-Granados N, AlSaidi $\mathrm{F}$ et al (2003) One-year outcomes in survivors of the acute respiratory distress syndrome. N Engl J Med 348(8):683-693

27. Lau HM, Lee EW, Wong CN, Ng GY, Jones AY, Hui DS (2005) The impact of severe acute respiratory syndrome on the physical profile and quality of life. Arch Phys Med Rehabil 86(6):1134-1140

28. Hsieh M-J, Lee W-C, Cho H-Y, Wu M-F, Hu H-C, Kao K-C et al (2018) Recovery of pulmonary functions, exercise capacity, and quality of life after pulmonary rehabilitation in survivors of ARDS due to severe influenza $A$ (H1N1) pneumonitis. Influenza Other Respir Viruses. 12(5):643-648
29. Tansey CM, Louie M, Loeb M, Gold WL, Muller MP, de Jager J et al (2007) One-year outcomes and health care utilization in survivors of severe acute respiratory syndrome. Arch Int Med 167(12):1312-1320

30. Wu F, Wang A, Liu M, Wang Q, Chen J, Xia S, et al. Neutralizing antibody responses to SARS-COV-2 in a COVID-19 recovered patient cohort and their implications. medRxiv : the preprint server for health sciences. 2020: 2020. 03.30.20047365

31. Ahmed H, Patel K, Greenwood DC, Halpin S, Lewthwaite P, Salawu A et al (2020) Long-term clinical outcomes in survivors of severe acute respiratory syndrome and Middle East respiratory syndrome coronavirus outbreaks after hospitalisation or ICU admission: a systematic review and meta-analysis. J Rehabil Med 52(5):jrm00063

32. Batawi S, Tarazan N, Al-Raddadi R, Al Qasim E, Sindi A, Al Johni S et al (2019) Quality of life reported by survivors after hospitalization for Middle East respiratory syndrome (MERS). Health Qual Life Outcomes. 17(1):101

33. Rodriguez-Morales AJ, Cardona-Ospina JA, Gutiérrez-Ocampo E, VillamizarPeña R, Holguin-Rivera Y, Escalera-Antezana JP et al (2020) Clinical, laboratory and imaging features of COVID-19: A systematic review and meta-analysis. Travel Med Infect Dis 34:101623

34. Thompson BT, Chambers RC, Liu KD (2017) Acute respiratory distress syndrome. N Engl J Med 377(6):562-572

35. Goyal P, Choi JJ, Pinheiro LC, Schenck EJ, Chen R, Jabri A et al (2020) Clinical characteristics of COVID-19 in New York City. N Engl J Med 382(24):23722374

36. Bhatraju PK, Ghassemieh BJ, Nichols M, Kim R, Jerome KR, Nalla AK et al (2020) COVID-19 in critically ill patients in the Seattle Region - case series. N Engl J Med 382(21):2012-2022

37. Wichmann D, Sperhake J-P, Lütgehetmann M, Steurer S, Edler C, Heinemann A et al (2020) Autopsy findings and venous thromboembolism in patients with COVID-19: a prospective cohort study. Ann Intern Med. 173(4):268-277

38. Burnham EL, Hyzy RC, Paine R 3rd, Coley C 2nd, Kelly AM, Quint LE et al (2013) Chest CT features are associated with poorer quality of life in acute lung injury survivors. Crit Care Med 41(2):445-456

39. Varatharaj A, Thomas N, Ellul MA, Davies NWS, Pollak TA, Tenorio EL et al (2020) Neurological and neuropsychiatric complications of COVID-19 in 153 patients: a UK-wide surveillance study. Lancet Psychiatry. 7(10):875-882

40. Zambrelli E, Canevini M, Gambini O, D'Agostino A (2020) Delirium and sleep disturbances in COVID-19: a possible role for melatonin in hospitalized patients? Sleep Med 70:111

41. Kotfis K, Williams Roberson S, Wilson JE, Dabrowski W, Pun BT, Ely EW (2020) COVID-19: ICU delirium management during SARS-CoV-2 pandemic. Crit Care (London, England) 24(1):176

42. Gardner PJ, Moallef P (2015) Psychological impact on SARS survivors: critical review of the English language literature. Can Psychol/Psychol Can 56(1): 123-135

43. Kemp HI, Corner E, Colvin LA (2020) Chronic pain after COVID-19: implications for rehabilitation. Br J Anaesth. 125(4):436-440

\section{Publisher's Note}

Springer Nature remains neutral with regard to jurisdictional claims in published maps and institutional affiliations.

\section{Submit your manuscript to a SpringerOpen ${ }^{\circ}$ journal and benefit from:}

- Convenient online submission

- Rigorous peer review

- Open access: articles freely available online

- High visibility within the field

- Retaining the copyright to your article

Submit your next manuscript at $>$ springeropen.com 